\title{
O PLANEJAMENTO ESTRATÉGICO COMO FERRAMENTA PARA A GESTÃO ESCOLAR: UM ESTUDO DE CASO EM UMA INSTITUIÇÃO DE ENSINO FILANTRÓPICA DA BAHIA/BA
}

\author{
A. B. C. CASTRO ${ }^{*}$; L. M. P. BRITO ${ }^{2}$; R. S. DOS SANTOS ${ }^{3}$ e J. H. DE S. VARELA ${ }^{4}$ \\ 'Instituto Federal de Educação, Ciência e Tecnologia do Rio Grande do Norte \\ ${ }^{2}$ Universidade Potiguar \\ ${ }^{3}$ Universidade Federal da Paraíba \\ ${ }^{4}$ Universidade Federal do Rio Grande do Norte \\ brunnicastro@hotmail.com*
}

Artigo submetido em janeiro/2015 e aceito em abril/2015

DOI: $10.15628 /$ holos.2015.2675

\section{RESUMO}

O cenário de constantes mudanças que ocorre nas organizações tem exigido uma gestão ágil e inteligente na qual o planejamento estratégico é crucial como ferramenta de adaptabilidade. Nesse sentido, o objetivo desta pesquisa é verificar como ocorre o planejamento estratégico em uma instituição de ensino filantrópica do Estado da Bahia na percepção de seus gestores chave. Optou-se por um estudo de caso e de campo, de abordagem quantitativo-descritiva. Utilizou-se de questionário e análise documental e os dados coletados foram analisados através de planilhas eletrônicas. Os resultados sinalizam que o planejamento ocorre conforme as definições teóricas da área de gestão escolar e administração, porém, tem-se um paradoxo, pois a instituição pesquisada não pratica planejamento estratégico, mas pratica plano de ação, que tem como foco as tarefas, atividades e objetivos detalhados para o curto prazo. Nesse caso, levantou-se um questionamento na pesquisa: planos de ação de curto prazo em instituições de ensino conseguem refletir a capacitação dos cidadãos que atuarão na realidade social no futuro?

PALAVRAS-CHAVE: Gestão escolar, gestão estratégica, planejamento estratégico.

\section{STRATEGIC PLANNING AS A TOOL FOR MANAGEMENT SCHOOL: A CASE STUDY IN A PHILANTHROPIC TEACHING INSTITUTION OF BAHIA/BA}

\begin{abstract}
The scenario of constant changes that occur in organizations has demanded an agile and intelligent management in which strategic planning is crucial as adaptability tool. In this sense, the objective of this research is to see how strategic planning is a philanthropic educational institution of the State of Bahia in the perception of their key managers. We opted for a case study and field of quantitative descriptive approach. We used a questionnaire and document analysis and data collected were analyzed using
\end{abstract}

spreadsheets. The results indicate that planning occurs as the theoretical definitions of school management and administration area, however, there is a paradox, because the research institution does not practice strategic planning, but practical action plan, which focuses on the tasks, activities and detailed objectives for the short term. In this case, there arose a question in the survey: short-term action plans in educational institutions can reflect the empowerment of citizens who will work in the social reality in the future?

KEYWORDS: School management, strategic management, strategic planning. 


\section{INTRODUÇÃO}

Neste tempo de desafios no cenário mundial para as organizações, as mudanças acontecem em meio a sociedade da informação, do conhecimento e da aplicação tecnológica. Trata-se de um ambiente de contínuas transformações nas relações sociais e econômicas, e nesse contexto as organizações perceberam que o mais importante era compreender as mutações deste mercado, pois poderiam ser a chave para o sucesso organizacional. Essa compreensão elevou a importância pela dimensão "estratégia", evidenciada no meio das organizações pelo Planejamento Estratégico.

O planejamento estratégico se constitui como uma função gerencial relevante em que a instituição se projeta para o futuro, delineando uma programação na qual os objetivos são definidos, estratégias são estabelecidas e recursos são alocados visando-se a manutenção das organizações no mercado. (MAXIMINIANO, 1995).

Porém, na prática, o processo de planejar estrategicamente ainda é um desafio, inclusive para as Instituições de Ensino (IE), foco desta pesquisa, devido a distância entre sua elaboração e sua implementação, pois existe, inclusive, uma letargia conceitual sobre o tema. Além disso, muitos gestores tem deixado de lado o planejamento estratégico e adotado planos de ação imediatos. O resultado disso tem sido uma sequencia de tentativas frustradas, que retardam a eficiência e eficácia organizacional, tais como: copiar a estratégia do concorrente, ir por um caminho que todos estão indo, consultorias intermináveis, decisões erradas etc.

Segundo Godoy et al. (2011, p.87), trazendo para o contexto da gestão escolar,

Um dos maiores desafios dos gestores educacionais, bem como, de suas instituições, é conceber e elaborar um processo contínuo, dinâmico e participativo de planejamento, principalmente adquirir a cultura estratégica, para tratar as possíveis situação-problema e ter uma visão objetiva dos resultados esperados.

Para Lück (2000, p.2), o que se observa, muitas vezes, no ambiente escolar é que:

[...] não tão raramente, gestores e profissionais em geral que se lamentam de estarem trabalhando como quem está "apagando incêndios", isto é, de estarem "sempre correndo atrás do prejuízo" e sendo conduzidos pelas situações variadas do cotidiano, pelas demandas inesperadas, tendo que responder rapidamente a elas e de tal forma que "não têm tempo para pensar, quanto menos para planejar". Esta forma de administrar por crise é estimulada e orientada por descobertas ocasionais e espontâneas, de caráter imediatista, por uma visão de senso comum e reativa da realidade e, portanto, limitada em seu alcance, muito influenciada pela tendência de se agir por tentativas e erros. Nesse caso, os acontecimentos determinam a ação de dirigentes escolares, em vez de, como seria próprio, os dirigentes, por meio de uma ação competente influenciarem os acontecimentos e a realidade.

Além disso, de acordo com Tachizawa e Andrade (2006), na prática, instituições de ensino típicas, em geral, enfrentam o exercício do planejamento, através da simples atuação em salas de aula e/ou da realização esporádica de projetos de pesquisas. 
A ausência de gestão escolar estratégica poderá causar ainda a falta de uma visão de futuro, dificultando-se a mudança no interior das organizações e a percepção tanto do macroambiente (composto de fatores bem amplos - legal/político, internacional, tecnológico, econômico, social e o ambiente natural - que afetam todas as instituições), do microambiente (fatores que sofrem um controle mais direto da instituição, tais como: estrutura organizacional, pessoas, gestores, administradores, diretrizes, tecnologia e cultura), quanto do ambiente tarefa (fatores que interagem diretamente com a instituição, como clientes, concorrentes, agências reguladoras, grupos de interesse especial e fornecedores). (TRIGUEIRO E MARQUES, 2012).

A partir desse cenário de mudanças e incertezas na gestão das IEs, segundo Perfeito (2007), teóricos da área de gestão estratégica nas IE, vem recolocando a dinâmica do funcionamento das IEs no centro de suas preocupações. Isto porque se reconhece que a educação numa sociedade globalizada e numa economia centrada no conhecimento, constitui valor estratégico para o desenvolvimento de qualquer sociedade. $\mathrm{O}$ autor propõe um esforço de compreender a relação escola-sociedade e como decisões internas no ambiente escolar podem capacitar os que atuarão na realidade social a tomar suas decisões acertadamente.

A afirmação de Perfeito (2007) problematiza ainda, a importância do planejamento estratégico, pois pode se associar ao que ela chamou de "decisões internas" para o ambiente escolar, já que, a finalidade de uma IE, é social, ou seja permitir a aprendizagem dos alunos, não somente pela aprendizagem, mas também para preparar cidadãos. Nesse sentido, Monteiro (2012), acrescenta ainda como finalidades de uma IE: alcançar as metas de matrículas e cobertura escolar, evitar a evasão escolar, qualificar os profissionais da educação, elevar os índices de aprovação e dirimir os índices de reprovação de alunos etc.

Diante disso questiona-se: como ocorre o planejamento estratégico na gestão de uma instituição de ensino do interior da Bahia/BA na percepção dos seus gestores chave?

A instituição de ensino pesquisada como foco desse trabalho, é filantrópica e se localiza numa cidade do interior do Estado da Bahia, mantida por uma empresa privada e que atende ao ensino Fundamental I e II em regime de internato com alternância e foi fundada em 1987.

Quanto a esta pesquisa, se justifica pela possibilidade de levantar medidas quantitativas sobre o desempenho de cada fase do planejamento estratégico aplicado a uma IE, bem como, por conhecer os caminhos de sucesso percorridos na prática do planejamento. Para os autores dessa investigação, trata-se de uma oportunidade de pesquisa aplicada que viabiliza conhecer como ocorre o planejamento em uma IE. O objetivo geral foi verificar como ocorre o planejamento estratégico numa instituição de ensino do interior do estado da Bahia na percepção de seus gestores chave. Para a consecução desta pesquisa, optou-se por um estudo de caso e de campo, de abordagem quantitativo-descritiva.

Além da introdução, o artigo explora o referencial teórico da área. Em seguida, são apresentados os procedimentos metodológicos, a análise dos resultados, considerações finais e as referências.

\section{FUNDAMENTOS TEÓRICOS}

Nessa seção, foi abordada a perspectiva conceitual sobre a Gestão Escolar, Gestão Estratégica e Planejamento Estratégico. 


\subsection{Gestão Escolar}

A Gestão Escolar, conforme Menezes (2002), foi criada para suprir um possível enfoque de um antigo termo da administração escolar que teve origem nos movimentos de abertura política do país, onde começaram então, a surgir novos conceitos e valores ligados à ideia de autonomia escolar.

O conceito evoluiu e já se discute, segundo Saporiti (2002, p. 21), que: "é preciso eliminar o conceito de que para administrar a escola basta boa vontade e honestidade. É um bom começo, mas não é tudo". A afirmação do autor levanta a reflexão sobre a importância do conhecimento que o gestor deve ter, não apenas com os aspectos propriamente pedagógicos, mas também com os avanços tecnológicos, métodos e técnicas administrativas e ferramentas de gestão, que venham a neutralizar os impactos negativos do ambiente em que a IE está inserida.

Ao se discutir a gestão numa perspectiva escolar, segundo Perfeito (2007), imediatamente se pensa no responsável por conduzir os processos administrativos e pedagógicos da IE: o diretor. A ele cabe articular a diversidade dar-lhe unidade e consistência na construção do ambiente educacional e promover a formação dos alunos. São desafios associados aos gestores escolares, conforme Bologna (2005, p.27):

[...] estar sempre alerta aos problemas de aprendizado para ajudar o professor a encontrar as melhores estratégias de ensino. Além de incentivar o uso de novas metodologias e tecnologias, o diretor deve promover a discussão permanente de assuntos pedagógicos e outros que permeiam a educação [...].

Bologna (2005), ainda coloca que: o gestor deve participar do planejamento e fazer o acompanhamento do trabalho docente, sendo um bom construtor de consensos, devendo estar sempre aberto às novas ideias e à diversidade, aceitando as opiniões e novas propostas que visem sempre melhorar a qualidade de ensino.

Ainda, conforme Libâneo (2001, p.224),

As pessoas envolvidas na administração da escola deverão exibir uma competência técnica que deve dizer respeito tanto ao conhecimento da coisa administrativa, ou seja, aos aspectos mais propriamente pedagógicos, quanto aos processos, métodos relacionados à atividade administrativa. [...].

Portanto, a gestão escolar se reflete atualmente na relação de interdependência entre o conhecimento dos gestores e a aplicação de métodos, técnicas e tecnologias; no processo participativo, e em pessoas qualificadas no fazer administrativo; sendo que, a organização deve estabelecer as condições gerais que permitam o seu funcionamento através dos diversos setores, quando se trata de ambiente tarefa ou mesmo dos órgãos e instituições que compõem o macroambiente, que regula, por exemplo, a legislação. (TACHIZAWA E ANDRADE, 2006).

Além da importância do gestor nas IE, um dos princípios básico da administração que vem merecendo destaque, devido a complexidade das IE, é o planejamento.

De acordo com Tachizawa e Andrade (2006, p.80-81):

A complexidade dessas instituições de ensino caracteriza-se, de um lado, pela pluralidade das áreas de ação, objeto do seu desempenho, compreendendo todo 
o universo do conhecimento humano, e, de outro, por entes educacionais em profunda interação com a sociedade, à qual tem de oferecer profissionais [...] portadores de uma formação qualitativa e quantitativamente adequada às exigências e necessidades dessa comunidade.

Em se tratando do planejamento nas IE, segundo Perfeito (2007, p.53):

Planejar implica um comprometimento com a ação. O planejamento só tem significância quando é implementado e avaliado de acordo com a consecução de seus objetivos; caso contrário, resumir-se-á a uma coletânea de intencionalidades que não trazem benefícios reais à organização. Um dos grandes desafios da gestão das instituições de ensino é desenvolver uma maior capacidade de resposta às demandas externas. Para isso, é necessário que seus gestores sejam capazes de utilizar diferentes abordagens de planejamento, a fim de que as instituições possam atingir seus objetivos e cumprir sua missão.

Para Nóbrega (2005), as estratégias de melhoria da qualidade educativa relacionadas à gestão escolar, entre elas o planejamento, normalmente, são resultados do processo de reforma/controle do Estado, ou seja, do macroambiente, apresentando-se configurações que dizem respeito à organização dos sistemas de ensino. Entretanto, Perfeito (2007) coloca que a gestão tem sido apresentada como um dos pontos centrais no processo de mudança dos sistemas educacionais, e essa centralidade dada à gestão não se refere apenas às esferas organizadoras do sistema educacional, mas também ao interior de cada IE em que são elaboradas propostas em prol da autonomia e da descentralização no trabalho.

\subsection{Gestão Estratégica}

A Gestão Estratégica é um conceito abrangente e relativamente novo. De acordo com Chiavenato (2003, p.234), "[...] podemos definir a estratégia como a mobilização de todos os recursos da empresa no âmbito global visando atingir os objetivos no longo prazo".

Para Sobral e Peci (2013), trata-se de um processo que consiste no conjunto de decisões e ações tomadas pelos gestores em nível estratégico, que visam proporcionar uma adequação entre a instituição e seu ambiente, de forma a permitir que ela alcance seus objetivos.

Conforme Perfeito (2007), é um processo de gestão que apresenta, de maneira integrada, o aspecto futuro das decisões institucionais, a partir da formulação da filosofia da instituição, sua missão, sua orientação, seus objetivos, suas metas, seus programas e as estratégias a serem utilizadas para assegurar sua implantação.

Portanto, a gestão estratégica é um processo que parte da realidade complexa e dinâmica da instituição, envolvendo a tomada de decisões e ações pelos gestores em nível estratégico, e isso força, ou pelo menos estimula os gestores a pensarem sobre o que é importante, e a se concentrarem sobre assuntos de relevância para alcançarem suas metas no longo prazo.

\subsection{Planejamento Estratégico}

O Planejamento Estratégico, foco desta pesquisa, é uma das fases da Gestão Estratégica, e conforme Tachizawa e Andrade (2006) não se pode tratar de um em separado do outro, pois o planejamento contribui para a eficácia da gestão das organizações a partir da tomada de 
decisões. O Planejamento Estratégico trata do processo de estabelecer objetivos e definir a maneira como alcança-los. (OLIVEIRA, 2007; CHIAVENATO, 2010).

Nesse sentido, conforme Chiavenato (2010), o planejamento ajuda o gestor a focar seu esforço, a dar um sentido de direção aos membros da instituição, a reduzir o impacto das mudanças do meio externo, maximizar a eficiência, definir os parâmetros de controle e no próprio autoconhecimento da instituição e das forças que a cercam no seu campo de atuação.

Porém, a partir da literatura da área (CHIAVENATO, 2010; RENNÓ, 2013; SOBRAL E PECI, 2013), percebe-se que, no Brasil, apesar de muitas organizações afirmarem que utilizam da metodologia do Planejamento Estratégico, ainda pairam dúvidas sobre o que realmente este vem a ser e como deve ser formulado.

Para Chiavenato (2003; 2010), a diferença entre utilizar e se beneficiar do planejamento estratégico, está diretamente relacionado com a constante necessidade de reavaliá-lo e reajustálo em função das mudanças do ambiente em que as instituições estão inseridas. Além disso, conforme Sobral e Peci (2013), o planejamento estratégico não deve ser considerado isoladamente, pois outras variáveis interferem no seu processo de elaboração, por exemplo, a cultura organizacional, ou seja, não basta construir bons planos em boas bases técnicas, o planejamento precisa ter um ambiente participativo para garantir a sua permanência e reavaliação constante, conforme as mudanças que ocorrem no mercado, assim, para Perfeito (2007), não se pode deixar de mencionar a grande importância que a comunidade escolar tem perante o sucesso dessa ferramenta, pois é a participação das pessoas que dará vida aos planos estratégicos, que se consolidarão com o tempo, reforçando a cultura do planejamento.

Outro destaque para o planejamento estratégico, é o que coloca Tachizawa e Andrade (2006), quando afirmam que, essa ferramenta serve para analisar os grandes problemas que afetam a instituição como um todo, ou seja, os problemas do nível estratégico da organização. Depois, no contexto das instituições esses objetivos devem ser detalhados nos níveis mais baixos, o tático e operacional, conforme pode ser visto na Figura 1.

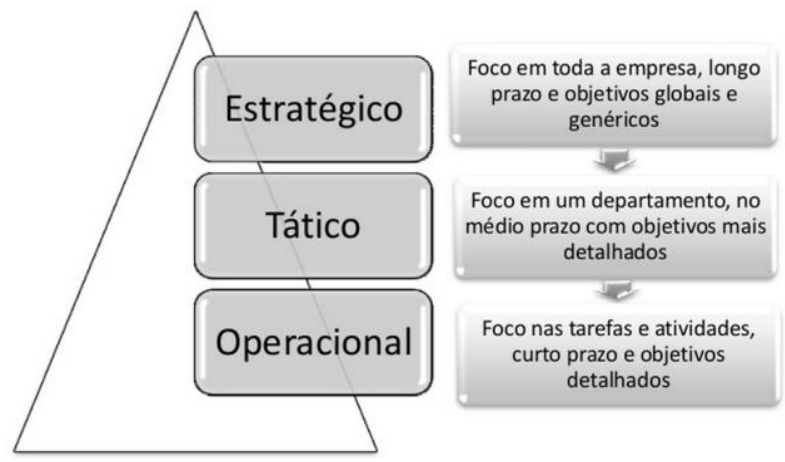

Figura 1: Níveis do planejamento. Fonte: Rennó (2013).

Os objetivos estratégicos elevam a importância do planejamento, pois conforme os autores, o nível mais baixo - o tático e o operacional - terão que tomar decisões e planejar seu próprio trabalho baseado nas decisões que o nível estratégico definiu. Dessa forma, o planejamento estratégico se refere à instituição de modo geral e é focado no longo prazo. $O$ planejamento estratégico tem uma forte visão do ambiente em que a instituição está inserida, ou seja, sobre como prepara-la para os desafios do meio ambiente (economia, beneficiários, governos, fornecedores etc.). 


\subsection{Modelos de Planejamento}

O Quadro 1 resume alguns modelos e contribuições dos autores, enfatizando seus elementos sobre o planejamento estratégico nas organizações.

QUADRO 1: Modelos de Planejamento para as organizações. Fonte: elaborado pelos autores.

\begin{tabular}{|c|c|c|}
\hline $\begin{array}{l}\text { Autor do } \\
\text { Modelo }\end{array}$ & Ano & Elementos do modelo \\
\hline Bryson & 1995 & $\begin{array}{l}\text { Modelo de planejamento estratégico a partir de conceitos determinantes, sendo: a } \\
\text { filosofia institucional; as atribuições institucionais; a missão e valores institucionais; } \\
\text { análise dos ambientes; o pensar estrategicamente; a implantação do planejamento e sua } \\
\text { retroalimentação. }\end{array}$ \\
\hline $\begin{array}{l}\text { Tachizawa e } \\
\text { Andrade }\end{array}$ & 2006 & $\begin{array}{l}\text { Modelo para a gestão de IE, cuja proposta de planejamento estratégico, propõe um } \\
\text { diagnóstico da situação e das oportunidades e ameaças que cercam as IE. Engloba as } \\
\text { seguintes fases: Análise ambiental; aspectos internos (pontos fortes e fracos); estratégia } \\
\text { vigente; missão versus campo de atuação; elaboração de missão, estratégias, objetivos e } \\
\text { ações estratégicas; e construção de plano estratégico (envolve políticas e diretrizes). }\end{array}$ \\
\hline $\begin{array}{l}\text { Schermerhorn } \\
\text { Jr. }\end{array}$ & 2008 & $\begin{array}{l}\text { Propõe } 5 \text { passos para o planejamento estratégico, sendo: definição dos objetivos: o que } \\
\text { queremos ou aonde queremos chegar? determinar sua situação atual: o quão longe } \\
\text { estamos dos nossos objetivos? desenvolver premissas sobre o futuro: prever os eventos } \\
\text { que poderão ocorrer no futuro (identificação de oportunidades e ameaças); analisar e } \\
\text { escolher entre as alternativas: gerar e analisar alternativas possíveis de ação; } \\
\text { implementar o plano e avaliar os resultados: executar o planejamento e avaliar os } \\
\text { resultados atingidos e corrigir os desvios. }\end{array}$ \\
\hline Rennó & 2013 & $\begin{array}{l}\text { Define } 6 \text { fases para o planejamento estratégico, sendo: definição do negócio; definição } \\
\text { da missão, visão e valores; análise interna; análise externa; formulação da estratégia e } \\
\text { implantação e controle. }\end{array}$ \\
\hline Sobral e Peci & 2013 & $\begin{array}{l}\text { Propõem } 5 \text { fases para o planejamento estratégico, sendo: diagnóstico da situação atual, } \\
\text { análise estratégica formulação estratégica, implementação estratégica e controle } \\
\text { estratégico. }\end{array}$ \\
\hline
\end{tabular}

Diante desses modelos, considerando-se o objetivo desse trabalho, optou-se pela abordagem dos autores Tachizawa e Andrade (2006) e Sobral e Peci (2013), pois Tachizawa e Andrade (2006) montam um diagnóstico da situação das organizações e das oportunidades e ameaças que a cercam, bem como, o diagnóstico do processo de execução e controle estratégico como ferramenta de verificação da estrutura do planejamento, justificando-se seu uso por ser aplicado ao contexto das instituições de ensino, conforme a Figura 2.

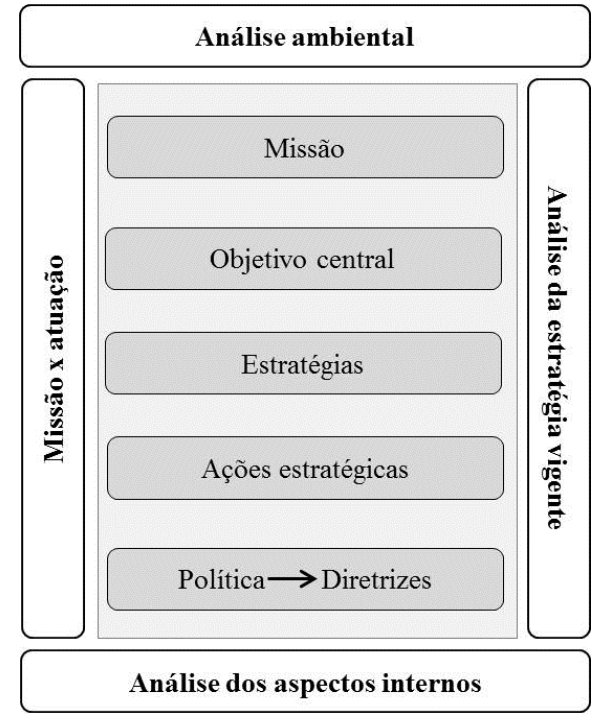

Figura 2: Visão metodológica do modelo. Fonte: Adaptado de Tachizawa e Andrade (2006). 
Enquanto Sobral e Peci (2013), apresentam uma melhor organização das dimensões/fases do planejamento, nas quais se enquadram a visão metodológica de Tachizawa e Andrade (2006), conforme a Figura 3.

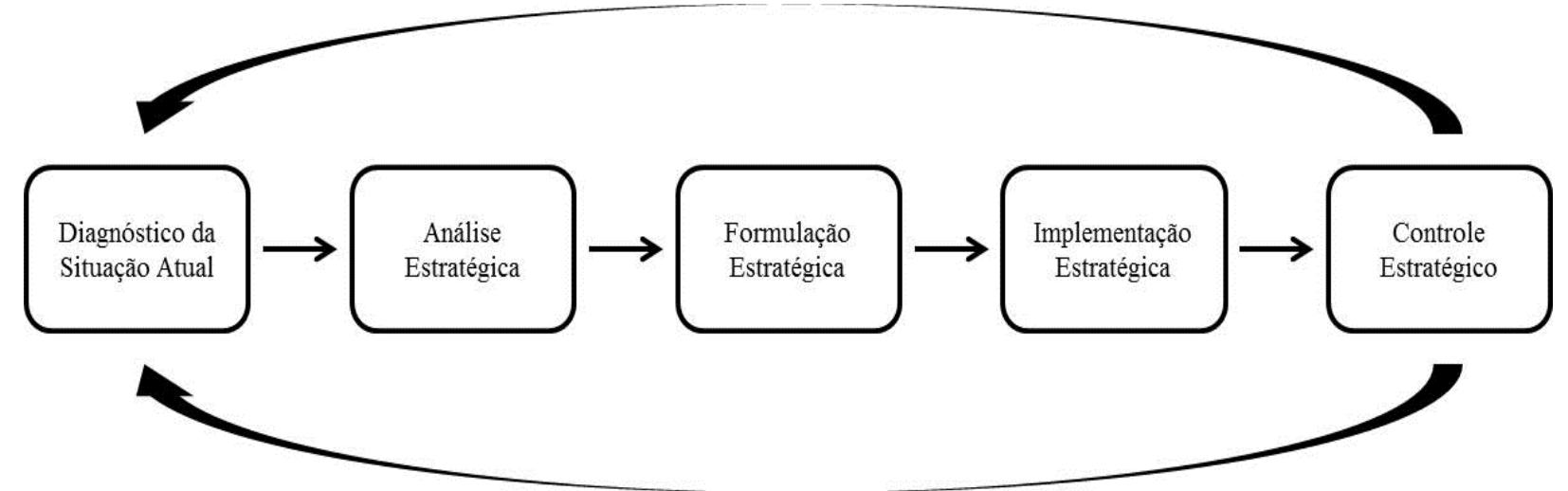

Figura 3: Fases da Administração Estratégica ligadas ao Planejamento Estratégico. Fonte: Adaptado de Sobral e Peci (2013).

O modelo dos autores Tachizawa e Andrade (2006), parte da compreensão do meio ambiente e sua relação com as IEs, permitindo-se delinear as estratégias genéricas inerentes a uma IE típica no processo de planejamento, ou seja, reforçam a necessidade da análise ambiental (do macroambiente, microambiente e ambiente tarefa), da análise das estratégias vigentes, da análise comparativa entre missão versus campo de atuação, da implementação com controle, da criação de cenários para projetar determinadas situações ou eventos com probabilidade de ocorrência, da definição de um objetivo central, estratégias etc. Para os autores, quando o gestor de uma IE tiver êxito em integrar todos na organização e fora dela, e unir os interesses destes aos objetivos preestabelecidos no plano estratégico, refluiriam os resultados que assegurariam o cumprimento da missão da IE.

Portanto, conforme Tachizawa e Andrade (2006), o planejamento estratégico na gestão escolar, deve ser um processo que requer o envolvimento de técnicos, docentes, gestores e a comunidade, visando-se garantir eficiência na implementação das estratégias institucionais, através da capacidade de (re)definição de sua missão, objetivos e metas, bem como, de selecionar as estratégias e meios para atingir tais objetivos em um período de tempo por meio da interação com o meio ambiente.

A sugestão dos autores, nesse sentido, é de que sejam criados grupos de trabalho, ou comitês com gestores que ocupem funções-chave para a consecução das atividades inerentes ao planejamento estratégico, definição de indicadores de gestão, de qualidade e de desempenho, e para análise de diagnóstico inicial, ou seja, o planejamento estratégico necessita refletir a condição particular que a IE assume em termos de campo de atuação, cursos a serem oferecidos, tipo de aluno a ser formado, recursos de docência e recursos tecnológicos.

Para compreensão dos componentes da visão metodológica de Tachizawa e Andrade (2006), tem-se:

- Análise ambiental: representa a gestão do serviço educacional no macroambiente, no microambiente e no ambiente tarefa. Para esse momento, os autores sugerem a realização de diagnósticos, para que os gestores das IEs saibam qual a real situação em que se encontra a IE e possam definir quais tipos de estratégias são mais adequados no 
momento do planejamento. Segundo os autores, a análise SWOT (acrônimo dos termos em inglês: Strengths = forças, Weaknesses = fraquezas, Opportunities = oportunidades e Threats $=$ ameaças), é uma das ferramentas mais comuns utilizadas nesse momento, pois é voltada para o pensamento estratégico, pois os cenários (ambiente) onde a instituição atua estão sempre em mudança.

- Missão: define as diferenças entre as IE mostrando suas necessidades sociais e identificando os alunos os quais procura servir, além de refletir suas tradições e sua visão de futuro. Portanto, o êxito da IE no cumprimento de sua missão seria proporcionar ao aluno, que se constitui o seu beneficiário cidadania e inclusão social;

- Objetivo central: alvo que a IE deve atingir, determinando-se para onde deve dirigir seus esforços. Dele depende a formulação das estratégias, traduzindo de forma mais concreta o foco de sua atenção;

- Estratégias: trata-se do que fazer para por em prática os objetivos estratégicos no horizonte de planejamento e, simultaneamente, reforçar a posição competitiva da IE;

- Ações estratégicas: são as que estabelecem o movimento do que fazer para por em prática estratégias no horizonte de planejamento;

- Políticas: são orientações de caráter geral que apontam os rumos e as linhas de atuação de uma determinada gestão. Devem ser apresentadas de forma a se tornarem de domínio do público interno da IE, explicitando as intenções de sua gestão;

- Diretrizes: são instruções e indicações para tratar e levar a termo um plano (ex. Projeto Político-Pedagógico, Plano de Desenvolvimento da Escola, Plano de Ensino etc.), uma ação (ex. aumentar o número de turmas de determinado curso) ou negociação (ex. formalizar uma parceria).

O ponto de intercessão entre os modelos de Tachizawa e Andrade (2006) e de Sobral e Peci (2013), poderá ser mais bem compreendido a partir do quadro abaixo:

QUADRO 2 - Intercessão entre os modelos de Tachizawa e Andrade (2006) e Sobral e Peci (2013). Fonte: elaborado pelos autores.

\begin{tabular}{|ll|}
\hline \multicolumn{1}{|c|}{ Sobral e Peci (2013) } & \multicolumn{1}{c|}{ Tachizawa e Andrade (2006) } \\
Diagnóstico da situação atual & Análise ambiental \\
Análise estratégica & Missão x atuação \\
Formulação estratégica & Análise interna e externa, missão, objetivo central, \\
Implementação estratégica & estratégias, ações estratégicas, políticas e diretrizes \\
Controle estratégico & Execução do planejamento estratégico \\
& Monitoramento do desempenho da IE frente aos \\
indicadores
\end{tabular}

O desenvolvimento desta pesquisa pode ser compreendido por meio dos procedimentos metodológicos e da análise dos resultados que se seguem.

\section{METODOLOGIA DA PESQUISA}

A pesquisa quanto à forma de abordagem do problema foi classificada como quantitativa (Gil, 2006), já que envolve métodos estatísticos com quantificação de variáveis, com o objetivo de obter respostas para a questão de pesquisa.

Do ponto de vista dos procedimentos técnicos, conforme Gil (2006); Yin (2010), a pesquisa foi classificada como estudo de caso e como pesquisa de campo. Utilizou-se do método 
descritivo que, conforme Vergara (2007), permite a descrição das características da amostra pesquisada e o estabelecimento de relações entre as variáveis da pesquisa.

Quanto à população, que "é um conjunto de elementos que possuem as características que serão objeto de estudo." (VERGARA, 2007, p.50), realizou-se um censo com os gestores chave (gestores do nível estratégico) da instituição de ensino pesquisada, durante a fase de coleta dos dados da pesquisa que ocorreu em Novembro de 2014, sendo: uma coordenadora, uma vice-diretora e uma diretora. A escolha dos gestores da IEs pesquisadas como público alvo da pesquisa se justifica, pois são eles que viabilizam o planejamento estratégico, bem como, o utilizam para tomada de decisão.

O instrumento de coleta de dados utilizado para atingir o objetivo da pesquisa foi um questionário com 25 questões fechadas elaboradas a partir do conteúdo teórico dos autores Tachizawa e Andrade (2006), agrupadas nas dimensões/fases do planejamento, conforme o modelo dos autores Sobral e Peci (2013).

Para o questionário foi utilizada uma escala ordinal de respostas gradativas com intensidade decrescente de um a três pontos, variando de "frequentemente" a "nunca". Apenas para as questões Q3, Q5, Q7, Q20 e Q23 do instrumento, foram descritas opções de múltipla escolha conforme o conteúdo teórico de Tachizawa e Andrade (2006).

Segundo Parasuraman (1991), a escala ordinal possui a propriedade de ordenar, ou seja, indica a ordem de ranking de um grupo de itens associados a uma determinada característica ou comportamento. Portanto, pode-se dizer, a partir dos gestores chaves que as respostas enquadradas na categoria 1 (frequentemente), por exemplo, representam uma intensidade de repetição maior em relação as demais opções de resposta. No entanto, com esse tipo de escala, não se tem como inferir a quantidade de repetições que determinada ação foi feita.

A aplicação do questionário foi feita com os gestores chave, ou seja, do nível estratégico da IE pesquisada e foram recolhidas pelos próprios pesquisadores. Em seguida, foram tratados os dados em planilhas eletrônicas a partir do agrupamento das respostas.

Também foi utilizado um questionário sócio-demográfico com cinco questões fechadas e análise documental, já que um dos pesquisadores tem acesso aos documentos institucionais e gestores chave da IE pesquisada, para auxiliar na identificação das ferramentas de planejamento estratégico utilizadas pela instituição.

\section{ESTUDO DE CASO}

A IE pesquisada é uma escola rural que atende ao ensino Fundamental I e II em regime de internato com alternância e foi fundada em 1987. A escola atende a mais de 600 alunos, com idades de 6 a 14 anos provenientes da zona rural de mais de 15 municípios. A evasão escolar gira em torno de $5 \%$, com índices de repetência de $16 \%$ e de aprovação de $79 \%$. O quadro de professores é composto de 16 educadores efetivos, com graduação e alguns com pós-graduação, e entre eles 5 atuam como técnicos em Agropecuária. Somando-se aos professores, tem-se uma equipe técnico-pedagógica considerada como os gestores chave da IE, sendo uma coordenadora, uma vice-diretora e uma diretora. Além disso, têm-se outros 50 colaboradores na área administrativa. (FUNDAÇÃO JOSÉ CARVALHO, 2014). 
A partir do Plano de Ação da IE pesquisada, tem-se:

- Missão: Promover, para os alunos do Ensino Fundamental, uma educação que vise à formação integral do indivíduo, valorizando sua riqueza cultural e possibilitando-lhe ser um agente transformador de sua realidade.

- Visão: Ser uma Escola Rural de referência a qual prima pela qualidade da educação oferecida, buscando, continuamente ser uma instituição aprendente.

- Crenças e Valores: Respeito por si mesmo, pelo próximo e pela natureza; ética e responsável; Solidariedade com todos que integram a comunidade escolar promovendo um clima de harmonia; Promoção da união como alicerce para a realização dos objetivos da Unidade Escolar; Exercício da tolerância nas relações interpessoais contribuindo para o equilíbrio e a boa convivência; Cultivo da honestidade valorizando-a como princípio necessário ao crescimento moral; Alimento contínuo da espiritualidade a fim de alicerçar o equilíbrio interior e as relações com o próximo.

- Objetivos: Garantir o cumprimento das propostas deste plano, acompanhando prazos e eficácia das mesmas; Informar os recursos necessários para realização das proposições; Avaliar as ações através do impacto na Unidade Escolar.

- Metas: Meta 1 - Oportunizar uma educação de qualidade, através do projeto pedagógico da Unidade Escolar; Meta 2 - Manter em 2014, o índice de aprovação em torno de 90\%; Meta 3 - Garantir em 2014 a difusão de conhecimentos e tecnologia do setor agropecuário, contribuindo para o desenvolvimento sustentável da agricultura familiar; Meta 4 - Manter em 2014 as parcerias e os convênios já estabelecidos. Ações: Desenvolvimento de projetos em parceria: plantas ornamentais e tropicais; mandiocultura e fruticultura; Meta 5 - Contribuir para o entrosamento e a harmonia dos integrantes da comunidade escolar e desta com a sociedade, em 2014; Meta 6 Assegurar o equilíbrio do custo da Unidade Escolar, em 2014. (FUNDAÇÃO JOSÉ CARVALHO, 2014).

\section{ANÁLISE DOS DADOS DA PESQUISA}

Na IE pesquisada, os gestores chave respondentes são mulheres, casadas, com faixa etária predominante entre 46 e 55 anos, com pós-graduação em nível de especialização na área de educação e apresentam experiência de mais de onze anos em função de gestão.

\subsection{Descrição e discussão dos resultados da pesquisa}

Considerando-se o objetivo desta pesquisa, a partir dos questionários aplicados conforme o modelo de Tachizawa e Andrade (2006) e Sobral e Peci (2013), percebeu-se quanto a fase de Diagnóstico da Situação Atual, que:

Frequentemente, na IE pesquisada, quando se trata da elaboração do planejamento estratégico, as gestoras chave consideram como importante a análise ambiental e algum diagnóstico a ser efetuado. Nesse sentido, conforme as gestoras entrevistadas, na análise ambiental são considerados o macroambiente, o microambiente e o ambiente tarefa.

Conforme a pesquisa aferiu-se que as variáveis que mais influenciam a IE, são:

- Macroambiente: inflação, política governamental, decisões econômicas, legislação, tecnologias educacionais, questões relacionadas ao meio ambiente, questões sociais, 
distribuição geográfica da população, crescimento vegetativo das matrículas e necessidade dos beneficiários;

- Microambiente: instituições de ensino concorrentes, clientes, prestadores de serviços;

- Ambiente tarefa: valores das pessoas, comprometimento das pessoas no trabalho e cultura organizacional.

Além disso, na IE pesquisada, frequentemente se busca identificar os fatores críticos de sucesso e são estabelecidos os pontos fortes e fracos da instituição. A partir da análise documental do Plano de Ação da instituição, percebeu-se que ela levanta os pontos fortes e fracos a partir da aplicação de Matriz SWOT, conforme Tabela 1.

Tabela 1: Análise Matriz SWOT da IE pesquisada

\begin{tabular}{|l|l|}
\hline \multicolumn{1}{|c|}{ OPORTUNIDADES } & \multicolumn{1}{c|}{ AMEAÇAS } \\
\hline $\begin{array}{l}\text { - Aumentar as parcerias com Empresas (públicas e } \\
\text { privadas) e Universidades; } \\
\text { - Explorar público alvo; }\end{array}$ & $\begin{array}{l}\text { - Aumento do prestígio das demais instituições de } \\
\text { ensino; }\end{array}$ \\
& $\begin{array}{l}\text { - Aumento da concorrência; } \\
\text { - A distância da comunidade; } \\
\text { FORÇAS }\end{array}$ \\
\hline $\begin{array}{l}\text { - Estrutura das demais Unidades de Ensino. } \\
\text { - Reconhecimento da qualidade de ensino; } \\
\text { - Definição de papéis e responsabilidades; } \\
\text { - Tradição e credibilidade; } \\
\text { - Foco na tradição do homem do campo; } \\
\text { - Comunicação organizacional e institucional; }\end{array}$ & - Falta de plano de carreira; \\
\hline
\end{tabular}

Fonte: Fundação José Carvalho (2014).

Coaduna com o colocado por Tachizawa e Andrade (2006), pois a análise SWOT é uma das práticas mais comuns voltada para o pensamento estratégico, pois pode trazer aos gestores uma melhor visão do campo de atuação das instituições a partir dos cenários (ambiente) que estão sempre em mudança onde elas atuam.

Portanto, as informações levantadas revelam, segundo Lück (2000) que, na IE pesquisada, se busca prever as demandas a partir do diagnóstico, evitando-se administrar seus recursos por crise, evitando-se descobertas ocasionais e espontâneas, de caráter imediatista, ou mesmo reativas da realidade. Nesse sentido, a IE não limita seu alcance e evita o processo de tentativa e erro, ou seja, a ação - diagnóstico, determina os acontecimentos.

Além disso, as informações levantadas na pesquisa ratificam o que coloca Nóbrega (2005), pois as melhorias na qualidade da ação educacional normalmente são influenciadas mais diretamente pelo macroambiente, principalmente quando dizem respeito a organização dos sistemas de ensino, que emanam de orientação do Estado, que podem ser verificados pelas variáveis político-governamentais, decisões econômicas, legislação e tecnologias educacionais, apontadas pelos respondentes na pesquisa.

Quanto a fase da Análise Estratégica, levantou-se a partir das respondentes que: a missão da IE é fruto da crença coletiva daqueles que fazem a instituição.

Além disso, frequentemente o planejamento estratégico é considerado um processo que contém decisões antecipadas sobre a linha de atuação a ser seguida para o cumprimento da missão, visão e estratégias da instituição, bem como, a IE busca definir (redefinir) sua missão, 
objetivos e estratégias em determinado período de tempo, por meio de constante interação com o meio ambiente (interno e externo) em que ela está inserida. E, na prática do planejamento estratégico, na instituição, são criados cenários para projetar situações ou eventos com probabilidade de ocorrência que poderão servir de base para elaboração de políticas ou planos de ação, para os níveis tático e operacional.

Os resultados encontrados na pesquisa demonstram, conforme Chiavenato (2010); Godoy et al. (2011), que na IE o planejamento é considerado como um processo contínuo/flexível possível de ser redefinido/reavaliado ou reajustado à medida dos acontecimentos no cenário ambiental. Nesse sentido, a partir de Trigueiro e Marques (2012), a instituição tem uma visão de futuro e se vale da análise do macroambiente, microambiente e ambiente tarefa para perpetuar a mudança no seu interior. A prática de criação de cenários apresentada nos resultados demonstra o quanto a IE se prepara para as ocorrências que poderão influenciar na sua mudança de percurso estratégico.

Para a fase de Formulação Estratégica, de acordo com as respondentes, a IE no processo de elaboração do planejamento estratégico se utiliza da participação de todos os seus trabalhadores (professores, coordenadores, diretores, administrativos etc.) e da participação da comunidade. Além disso, são criados comitês ou grupos de trabalho ou grupos temáticos com os trabalhadores e gestores chave da instituição para refletirem sobre as estratégias que assumirão em termos de campo de atuação, cursos a serem ofertados, perfil do alunado, recursos de docência, recursos tecnológicos etc.

O processo de participação das pessoas na construção do planejamento estratégico é ressaltado tanto por Godoy et al. (2011), quanto por Sobral e Peci (2013), que afirmam que, o planejamento participativo garante a sua permanência (do planejamento estratégico) e sua consolidação com o tempo, incorporando-se na cultura da organização. Bologna (2005), ainda ressalta o papel dos gestores no processo participativo de construção de consensos, pois devem estar sempre abertos às novas ideias e à diversidade, aceitando as opiniões e novas propostas para melhorar a qualidade do ensino, de modo que a instituição possa atingir sua missão.

Além disso, no processo de participação dos trabalhadores e gestores da IE, também se busca refletir sobre as principais decisões já proferidas nos últimos tempos e ao analisar sua missão, visão, objetivos versus campo de atuação, também se busca identificar as atividades que podem ser acrescidas ou reduzidas com vistas a alcançar sua missão.

Segundo Matos e Chiavenato apud Barbosa e Brondani (2004), identificar as mudanças ocorridas nos últimos anos e se valer delas para tomada de decisão, reflete que a instituição busca a aprendizagem contínua a partir da identificação das principais decisões tomadas nos últimos tempos, se aproximando de sua visão de futuro, ou seja, ser uma organização aprendente.

O planejamento participativo no caso da IE, bem como, a capacidade de refletir sobre decisões anteriores e mediar sobre atividades que podem ser acrescentadas ou reduzidas para o alcance da missão institucional, pode ser fruto da experiência das suas gestoras chave, pois apresentam mais de onze anos em função de gestão, e da qualificação das mesmas, pois possuem formação adequada para a área da educação. Esse perfil das gestoras, coaduna com Libâneo (2001) quando coloca que as pessoas envolvidas na administração escolar deverão exibir competências técnicas, tanto dos aspectos propriamente pedagógicos, quanto dos processos e 
métodos relacionados com a atividade administrativa, e essa competência pode ser adquirida pela experiência e pela educação formal dos gestores das instituições de ensino.

Quanto a fase de Implementação Estratégica, todas as gestoras chave afirmaram na pesquisa que, como elemento inseparável das fases de Implementação Estratégica e da próxima fase, a de Controle Estratégico, são utilizados indicadores de gestão para medir o desempenho da IE em cada fase do planejamento, bem como, as gestoras da IE pesquisada acompanham a execução do planejamento para garantir a eficiência e eficácia no direcionamento dos recursos para o alcance da missão, visão e objetivos da instituição no curto prazo (dois anos).

Levanta-se aqui, conforme Chiavenato (2010); Matos e Chiavenato apud Barbosa e Brondani (2004), um questionamento, pois para os autores citados, quando se trata de planejamento estratégico, trata-se de uma função de longo prazo, ou seja, acima de quatro anos; porém, no caso da IE pesquisada, apesar de utilizarem elementos do planejamento estratégico, seu estudo de caso, revelou que desenvolvem apenas um Plano de Ação no curto prazo (dois anos).

Portanto, não se trata, conforme Rennó (2013) de um planejamento estratégico com foco em toda a organização e com objetivos globais e genéricos, mas de um planejamento, diga-se plano de ação, com foco nas tarefas e atividades e objetivos detalhados para o curto prazo.

$\mathrm{Na}$ fase de Controle Estratégico, a IE, na percepção de suas gestoras chave mantém controle da execução do planejamento através de indicadores de qualidade e desempenho, sistemas de informação, e toma medidas corretivas sempre que existirem desvios significativos no foco estratégico da organização, bem como, depois de formulado, o planejamento é revisado e pode ser realinhado se houverem mudanças no meio ambiente em que a instituição está inserida.

Os principais indicadores utilizados pelas gestoras chave para monitorar o desempenho da IE, são: número de horas-aula vs. número de professores, número de professores vs. número de disciplinas, custo total anual vs. número de alunos, índice de reprovação dos alunos, índice de repetência dos alunos e o índice de desistência/evasão dos alunos.

Os indicadores apresentados como de controle e monitoramento do planejamento da IE, se aproximam dos citados por Monteiro (2012), como determinantes para a tomada de decisão internamente em instituições de ensino, em vista dos resultados positivos de uma IE na sua realidade social, pois permitem acompanhar o alcance das metas definidas pela instituição, identificar avanços, melhorias de qualidade, correção de problemas, necessidades de mudança etc.

Portanto, o planejamento estratégico na IE pesquisada ocorre a partir da análise do ambiente em que a instituição está inserida, sendo considerados, o macroambiente, o microambiente e o ambiente tarefa, bem como, é considerado algum diagnóstico inicial a ser efetuado e se busca identificar os fatores críticos de sucesso a partir da identificação dos pontos fortes e fracos em seu desempenho.

Além disso, na IE se busca definir (redefinir) sua missão, objetivos e estratégias em determinado período de tempo, por meio de constante interação com o meio ambiente (interno e externo), e, são criados cenários para projetar situações ou eventos com probabilidade de ocorrência que poderão servir de base para elaboração de políticas ou planos de ação. 
O planejamento estratégico na IE se apresenta como uma atividade participativa onde todos os profissionais da instituição e a comunidade contribuem e também participam de comitês e grupos de trabalho para refletirem sobre as estratégias que assumirão, a partir das decisões tomadas em tempos anteriores, e com o objetivo de identificar atividades que possam ser reduzidas ou acrescidas para o cumprimento de sua missão.

Também são utilizados indicadores de gestão para medir o desempenho da IE em cada fase do planejamento e tomadas medidas corretivas sempre que existirem desvios significativos no foco estratégico da organização. Além disso, depois de formulado, o planejamento é revisado e pode ser realinhado se houverem mudanças no meio ambiente em que a instituição está inserida. Os gestores da IE acompanham a execução do planejamento para garantir a eficiência e eficácia no direcionamento dos recursos para o alcance da missão, visão e objetivos da instituição no curto prazo (dois anos).

Porém, não se trata de um planejamento estratégico com foco em toda a organização e com objetivos globais e genéricos; mas de um Plano de Ação com foco nas tarefas e atividades e objetivos detalhados para o curto prazo.

\section{CONSIDERAÇÕES FINAIS}

A pesquisa sinalizou que o Planejamento Estratégico tem papel fundamental no processo decisório, na definição das estratégias e planos de ação para o alcance da missão, visão, objetivos e estratégias institucionais, pois visa amoldar os pontos fortes e fracos, oportunidades e ameaças, levando-se em consideração o ambiente interno e externo do campo de atuação da IE pesquisada, pois a partir do seu Plano de Ação, notou-se o uso da matriz SWOT como ferramenta de compreensão dos fatores influenciadores do contexto da IE.

O planejamento na IE, na percepção de suas gestoras, ocorre de forma contínua, pois ficou caracterizado que na instituição se utiliza das projeções de anos anteriores e análises ambientais para elaborar/rever suas estratégias; é um processo participativo, pois envolve todos os trabalhadores e a comunidade em grupos ou comitês de trabalho; a IE trata as possíveis situações-problema e busca ter uma visão objetiva e antecipada dos resultados esperados, evitando-se uma postura reativa da realidade.

Além disso, o planejamento na IE pesquisada, não se trata de uma coletânea de intencionalidades, mas de uma ferramenta de desenvolvimento institucional para prover uma maior capacidade de resposta às demandas externas, alcançar sua missão de promover, para os alunos do Ensino Fundamental, uma educação que vise à formação integral do indivíduo, valorizando sua riqueza cultural e possibilitando-lhe ser um agente transformador de sua realidade, a partir de suas estratégias, bem como suas metas. O planejamento estratégico no contexto da IE pesquisada, também poderá reduzir o impacto das mudanças do meio externo e maximizar a eficiência da organização, através do controle e do próprio autoconhecimento da instituição sobre suas forças, oportunidade, fraquezas e ameaças no seu campo de atuação.

A pesquisa também revelou que as gestoras da IE não estão preocupadas somente com os aspectos pedagógicos, mas também com os avanços tecnológicos, métodos e técnicas administrativas de gestão, e isso pode ser explicado pela competência técnica das gestoras quanto a sua experiência e formação em educação. 
A IE pesquisada, no processo de planejamento, também pode estar tentando adquirir ou consolidar uma cultura de estratégia, de planejamento estratégico e aprendizagem no seu interior, pois busca diagnosticar as bases dos problemas e as possibilidades de superá-los; entretanto, cultura se detecta a longo prazo, e nesse caso, tem-se que o planejamento da IE é um processo de curto prazo feito através de planos de ação. Além disso, a IE contribui para o desenvolvimento social, ao entender, através do planejamento, que suas decisões internas poderão se refletir no desenvolvimento da sociedade local através da preparação de cidadãos.

A constatação de que a IE não concebe planejamento estratégico como uma atividade de longo prazo, mas planos de ação versus sua atuação na educação como um processo de preparação de cidadãos para a sociedade, levanta um paradoxo e uma questão: planos de ação de curto prazo em IEs conseguem refletir a capacitação dos que atuarão na realidade social no futuro, bem como a preparação de cidadãos para a sociedade? Tem-se então, uma limitação desse estudo, pois a IE pesquisada, apesar de utilizar elementos do planejamento estratégico e envolver os gestores chave, do nível estratégico, na sua construção, elabora apenas planos de ação de curto prazo.

\section{REFERÊNCIAS}

1. BARBOSA, E. R.; BRONDANI, G. Planejamento Estratégico Organizacional. Revista Eletrônica de Contabilidade, Vol. 1(2), Dez-Fev, UFSM, 2004.

2. BOLOGNA, José Ernesto. Qual o segredo do sucesso de um gestor? Revista Nova Escola, São Paulo SP, n. 188, p. 26-28, dez., 2005.

3. BRYSON, J. Strategic Planning for Public and Nonprofit Organizations (rev. edn), San Francisco, CA: Jossey Bass, 1995.

4. CHIAVENATO, Idalberto. Teoria Geral da Administração. 7. Ed. Rev. e Atual. - Rio de Janeiro: Elsevier, 2003.

5 . Administração nos novos tempos. 2a ed. Rio de Janeiro: Elsevier, 2010.

6. OLIVEIRA, Djalma de Pinho R. de. Planejamento Estratégico: conceitos, metodologias e práticas. 24. Ed. São Paulo: Atlas, 2007.

7. Fundação José Carvalho. Disponível em: <http://www.fjc.org.br/unidade.php?id=28>. Acesso em: 18 de Setembro de 2014.

8. GIL, A. Carlos. Método e técnicas de pesquisa social. 5. Ed. São Paulo: Atlas, 2006.

9. GODOY, Valdir A.; ROSA, Marcelo R. BARBOSA, Flávio L. O planejamento estratégico como ferramenta para a gestão educacional no processo decisório dentro das IES. Revista Científica, Vol. 3, no 3, p. 77-89, 2011.

10. LIBÂNEO, José Carlos. Organização de Gestão da Escola, 4. Ed. Goiânia: Alternativa, 2001.

11. LÜCK, H. Gestão Escolar e a Formação de Gestores. Brasília: Ed. Azeredo, 2000.

12. . A aplicação do planejamento estratégico na escola. Revista Gestão em Rede, n. 19, Abr, p. 8-16, 2000.

13. MAXIMINIANO, Antonio C. A. Introdução à Administração. 4. Ed. São Paulo: Atlas, 1995. 
14. MENEZES, Ebenezer T. de; SANTOS, Thais H. dos. Gestão escolar (verbete). Dicionário Interativo da Educação Brasileiro - EducarBrasil. São Paulo: Midiamix Editora, 2002. Disponível em: http:// www.educabrasil.com.br/eb/dic/dicionario.aspid=37, Acesso em: 28 de Setembro de 2014.

15. MONTEIRO, Raquel A. Planejamento estratégico como instrumento de gestão escolar: análise na escola de ensino médio e profissional Florestan Fernandes em Acaraú-CE. Campina Grande: Realize Editora, 2012.

16. NÓBREGA, C. L. O Plano de Desenvolvimento da Escola (PDE) numa perspectiva de governo democrático e popular: uma análise da experiência na Rede de Ensino do Recife - PE. 2005. Dissertação (Mestrado em Educação) - Universidade Federal de Pernambuco, Recife. Disponível em: <https://www.ufpe.br/ceadmoodle/file.php/1/coord_ped/sala_3/arquivos /CRISTIANE_LIBERATO_DA_NOBREGA.pdf>. Acesso em: 20 de Dezembro de 2014.

17. PARASURAMAN, A. Marketing research. New York: Addison-Wesley Publishing Co, 1991.

18. PERFEITO, Cátia D. F. Planejamento Estratégico como Instrumento de Gestão Escolar. Revista Educação Brasileira. Brasília, v. 29, n. 58 e 59, p. 49-61, jan./dez. 2007.

19. RENNÓ, Rodrigo. Administração Geral para concursos. Rio de Janeiro: Elsevier, 2013.

20. SAPORITI, Rodrigo. Seja um Gestor Educacional. Revista Profissão Mestre. Curitiba-PR, v. 3, n. 35, p. 20-22, Agosto. 2002.

21. SOBRAL, Filipe; PECl, Alketa. Administração: teoria e prática no contexto brasileiro. 2. Ed. São Paulo: Pearson Education do Brasil, 2013.

22. SCHEMERHORN JR., J. R. Management. 9. Ed. Hoboken: Wiley \& Sons, 2008.

23. TACHIZAWA, Takeshy; ANDRADE, Rui Otávio B. de. Gestão de Instituições de Ensino. 4. Ed. Ver. e Ampl. Rio de Janeiro: Editora FGV, 2006.

24. TRIGUEIRO, Francisco M. C.; MARQUES, Neiva de A. Teoria da Administração I. 2. Ed. Reimp. Florianópolis: Departamento de Ciências da Administração, UFSC, 2012.

25. VERgARA, S. C. Projetos e relatórios de pesquisa em administração. 11. Ed. São Paulo: Atlas, 2007.

26. YIN, Robert K. Estudo de Caso: Planejamento e Métodos. 4. Ed. Porto Alegre: Bookman, 2010. 